\title{
MEASURING EFFECTIVENESS IN A HIERARCHICAL SYSTEM
}

\author{
B. K. Mangaraj \\ XLRI-Xavier School of Management, Jamshedpur, INDIA \\ E-mail : mangaraj@xlri.ac.in
}

\begin{abstract}
Effectiveness is a major criterion of performance measurement that explains the degree to which goals are attained. This paper deals with developing a measure of effectiveness of alternatives with respect to multiple number of criteria, which are organized in a hierarchical structure. A multi-criteria decisionmaking framework is used to assess this value numerically. The methodology is a three-step process that involves an analytic hierarchy process followed by a multi-objective decision-making model and a multi-attribute decision-making model. In the first step, the procedure generates the weights of the criteria by a pairwise comparison method using Saaty's ordinal scale. The weights of the alternatives are also obtained by the same method with respect to the criteria individually. The second step solves a multi-objective linear programming model for maximizing the effectiveness criteria taking into consideration the weights of the alternatives for the formulation of these criteria. The solution of this model involves "Min" followed by "Average" aggregation operators for combining the criteria that results in the highest common attainment level of the criteria, which acts as a benchmark for the alternatives. The third step evaluates effectiveness of each alternative as its relative closeness to the benchmark. For this, it becomes necessary to re-standardise the weights of the alternatives with respect to the benchmark in order to find out the average values and average distances of the alternatives from the benchmark. This helps in getting the relative closeness of each alternative from the benchmark that lies in the range of 0 to 1 . To illustrate the applicability of the model, the proposed methodology is then applied to measure the effectiveness of a human resource information system along four major human resource functions for six factors obtained in a factor analysis of responses from employees of an organization in a questionnaire survey.
\end{abstract}

Key words: effectiveness, analytic hierarchy process, benchmark, multi-criteria decision analysis.

\section{Introduction}

Effectiveness is generally a key concept in performance measurement, be it for a product, programme or even an organization (Mouzas, 2006). It is measured as the degree to which the criteria involved accomplish their goals (Marsh and Bailey, 2013). Thus, one can define organizational effectiveness, system effectiveness, market effectiveness, teaching effectiveness, development effectiveness etc., depending on the context in which the term is used. For instance, market effectiveness, can be explained and measured based on customer satisfaction along several criteria, viz., price, quality, brand etc. However, the literature does not show any specific methodology for the measurement of effectiveness. This paper explains the concept of effectiveness mathematically in a multi-criteria decision analysis framework involving multiple number of criteria as well as alternatives based on preferential data in Saaty's (1980) scale.

\section{Literature Review}

Golany (1988) presented an interactive multi-objective linear programming (MOLP) procedure in extending data envelopment analysis (DEA) for the introduction of benchmarking in effectiveness analysis. He used an empirical production function based on the observed inputs and outputs to generate many possible efficient positions. The objective function tries to maximize weighted linear sum of the outputs where the weight of each output represents its average value of the same output for the decision making units (DMUs) under consideration. By providing a support mechanism in an interactive manner, 
the DMUs were allowed to choose among them the one seen as most effective, which can be considered as the benchmark. In another paper, Golany and Tamir (1995) considered effectiveness not by maximizing the sum of the outputs, but rather by reaching a certain output threshold. The new variable obtained by subtracting the output variable from the threshold can be incorporated in the objective function for minimization. This approach presents the concept of goals in effectiveness measurement. But in these methods, the linear decision functions or linear goals are purely compensatory in nature. The advantage in one criterion can compensate the disadvantage in other. However, in the next section, the proposed methodology employs a multi-objective decision-making model that uses "Min" followed by "Average" aggregation operators to determine a benchmark for the alternatives in a competitivecum-compensatory way. This model is then supplemented by a multi-attribute decision-making model to measure the effectiveness of these alternatives.

\section{Methodology}

\section{Step-1}

(a) Assessment of the normalised weights of the criteria by employing an analytic hierarchy process of Saaty (1980). Let there be m number of criteria, whose weights are $W_{i}: i=1,2, \ldots, m$.

(b) Assessment of the normalised weights of the alternatives with respect to these criteria individually by using the same process again. Let there be $\mathrm{n}$ number of alternatives, whose weights are $a_{i j}: i=1,2, \ldots, m ; j=1,2, \ldots, n$.

(c) Find the maximum and minimum values of $a_{i j}$ based on for each $i$.

$a_{i j}^{M a}$ : Maximum value of $a_{i j}$ for each $i=1,2, \ldots, m$;

$a_{i j}^{M i}$ : Minimum value of $a_{i j}$ for each $i=1,2, \ldots, m$.

\section{Step-2}

To determine a set of effectiveness weights $e_{j}: \mathrm{j}=1,2, \ldots, \mathrm{n}$ that simultaneously maximizes all the weighted effectiveness criteria. These criteria are linear functions of $a_{i j}$ with respect to overall effectiveness weights $e_{j}$ for the $j^{t h}$ alternative. Hence, it becomes necessary to formulate a multiobjective linear programming (MOLP) model that finds out $e_{j}: \mathrm{j}=1,2, \ldots, \mathrm{n}$, which

Maximizes $\sum_{\mathrm{j}} W_{i} e_{j} a_{i j}: \mathrm{i}=1,2, \ldots, \mathrm{m}$.

$$
\text { s.t. } \quad \sum_{\mathrm{j}} e_{j}=1
$$

and

$$
e_{j} \geq 0
$$

To find out a maximum common attainment level $\lambda$ for all the effectiveness criteria as the basic requirement to determine the benchmark, the "Min" aggregation operator is used to combine all the effectiveness criteria into a decision criterion, which is to be maximized. Hence, model (1) is reduced to the following competitive decision model as:

$$
\begin{aligned}
& \operatorname{Max} \lambda \\
& \text { s. t. } \quad \lambda \leq\left(\sum_{\mathrm{j}} e_{j} \cdot a_{i j}-a_{i j}^{M i}\right) /\left(a_{i j}^{M a}-a_{i j}^{M i}\right) \quad: \mathrm{i}=1,2, \ldots, \mathrm{m} . \\
& \\
& \quad \sum_{\mathrm{j}} e_{j} \quad=1 \\
& \text { and } \quad e_{j} \geq 0
\end{aligned}
$$

Let $\bar{e}$ be the optimum basic feasible solution of the linear programming (LP) model (2) that results in the maximum value of $\lambda=\lambda^{*}$ and gives a compromise solution for the model (1), which may considered as the benchmark. At this point, all the effectiveness criteria attains their highest common value $\lambda^{*}$. 
However, this solution may not be efficient for the model (1). In that case, it may be extended by a compensatory decision model as:

$$
\begin{array}{ll} 
& \operatorname{Max} \frac{1}{m} \sum_{\mathrm{i}} W_{i} \mathrm{E}_{i} . \\
\text { s.t. } \quad & \mathrm{E}_{i}=\left(\sum_{\mathrm{j}} e_{j} \cdot a_{i j}-a_{i j}^{M i}\right) /\left(a_{i j}^{M a}-a_{i j}^{M i}\right): \mathrm{i}=1,2, \ldots, \mathrm{m} . \\
& \mathrm{E}_{i} \geq \lambda^{*} \\
& \sum_{\mathrm{j}} e_{j}=1 \\
\text { and } \quad e_{j} \geq 0
\end{array}
$$

The solution of the LP model (3) is efficient for the multi-objective model (1) having the highest common attainment level of the effectiveness criteria.

\section{Step-3}

In order to assess the effectiveness value of the alternatives, it is necessary to standardise the range of each criterion with respect to the benchmark as well as its highest (positive ideal $\left(I^{+}\right)$) and lowest (negative ideal $\left(I^{-}\right)$) values. As the benchmark is a compromise solution of the effectiveness criteria, a linear interpolation is used to estimate the marginal value functions $r a_{i j}$ in a piece-wise linear form in the interval $\left[I^{-}, I^{+}\right]$. The function is defined as:

$r a_{i j}= \begin{cases}\frac{a_{i j} \text { Benchmark }}{I^{+}-\text {Benchmark }} & \text { for Benchmark } \leq a_{i j} \leq I^{+} \\ \frac{a_{i j} \text { Benchmark }}{\text { Benchmark-I } I^{-}} & \text {for } I^{-} \leq a_{i j} \leq \text { Benchmark }\end{cases}$

Clearly $r a_{i j}$ has a value in the range $[-1,1]$ placing the benchmark point at $(0,0,0)$.

Based on the marginal values of alternatives along the criteria: $i=1,2, \ldots, \mathrm{m}$., two measures of effectiveness relative to the benchmark are defined as:

Definition 1: Average value $\left(A V^{R}\right)$ : It is the arithmetic mean of marginal values of an alternative along the criteria. Hence, $A V^{R}{ }_{i j}=\sum W_{i}\left(r a_{i j}\right) \quad$ for $\mathrm{j}=1,2, \ldots, \mathrm{n}$.

Definition 2: Average distance $\left(\boldsymbol{A} \boldsymbol{D}^{\boldsymbol{R}}\right)$ : It is the overall distance of an alternative from the benchmark along the criteria in terms of marginal values. Mathematically, it is expressed as:

$A D^{R}=\sqrt[2]{W_{i}\left(\sum r a_{i j}^{2}\right)}$, for $\mathrm{j}=1,2,3, \ldots, \mathrm{n}$.

It may be observed that, two alternatives having the same average value may differ in their respective average distances from the benchmark. In that case, the alternative with lesser average distance is more effective than the other. Hence, the measure of effectiveness becomes a ratio of the average value to the average distance, which can be normalised to have a value for an alternative in the range 0 to 1 .

Definition 3: Effectiveness measures relative closeness of an alternative from the benchmark. Mathematically, it is expressed as $\frac{1+A V^{R}}{1+A D^{R_{j}}}$, where its value lies in the range 0 to 1 .

\section{Model Analysis}

The model is applied to measure the effectiveness of a human resource information system (HRIS) along four human resource criteria as mentioned in table-1. Six effectiveness factors of the HRIS were obtained from a factor analysis of responses from the employees of an organization in a questionnaire survey. The same employees were also asked to provide their pair-wise comparison data for the criteria 
as well as factors with respect to the criteria in Saaty's scale. The AHP methodology was used to calculate the weights of the criteria as well as factors individually. Only consistent matrices were considered and the weights were averaged across employees for the purpose of constructing the table1. The relative weight as well as the rank of the factors based on the weighted criteria are presented in table1.

Table: 1: Criteria-factors matrix for the HRIS

\begin{tabular}{|l|l|l|l|l|l|l|}
\hline Factors & $\begin{array}{l}\text { Recruitment } \\
(0.12)\end{array}$ & $\begin{array}{l}\text { Performance } \\
\text { appraisal } \\
(0.29)\end{array}$ & $\begin{array}{l}\text { Grievance } \\
\text { redressing } \\
(0.23)\end{array}$ & $\begin{array}{l}\text { Retirement } \\
\text { \& voluntary } \\
\text { vacation } \\
(0.36)\end{array}$ & $\begin{array}{l}\text { Relative } \\
\text { weight }\end{array}$ & Rank \\
\hline $\begin{array}{l}\text { Quick and easy } \\
\text { access to } \\
\text { information }\end{array}$ & 0.12 & 0.18 & 0.15 & 0.16 & 0.159 & 4 \\
\hline $\begin{array}{l}\text { Centralized } \\
\text { information }\end{array}$ & 0.22 & 0.20 & 0.17 & 0.13 & 0.170 & 2 \\
\hline $\begin{array}{l}\text { Easy } \\
\text { administration } \\
\text { of HR functions }\end{array}$ & 0.17 & 0.15 & 0.20 & 0.14 & 0.160 & 5 \\
\hline $\begin{array}{l}\text { Faster HR } \\
\text { transactions }\end{array}$ & 0.20 & 0.13 & 0.14 & 0.18 & 0.159 & 4 \\
\hline $\begin{array}{l}\text { Reliability of } \\
\text { information }\end{array}$ & 0.18 & 0.12 & 0.16 & 0.20 & 0.165 & 3 \\
\hline $\begin{array}{l}\text { Faster } \\
\text { communication }\end{array}$ & 0.11 & 0.22 & 0.18 & 0.19 & 0.187 & 1 \\
\hline
\end{tabular}

Table: 2: Effectiveness measures for the factors of HRIS

\begin{tabular}{|l|l|l|l|l|}
\hline Factors & $\begin{array}{l}\text { Average } \\
\text { value } \\
\left(A V^{R}\right)\end{array}$ & $\begin{array}{l}\text { Average } \\
\text { distance } \\
\left(A D^{R}\right)\end{array}$ & Effectiveness & Rank \\
\hline $\begin{array}{l}\text { Quick and easy } \\
\text { access to } \\
\text { information }\end{array}$ & -0.218 & 0.491 & 0.524 & 3 \\
\hline $\begin{array}{l}\text { Centralized } \\
\text { information }\end{array}$ & -0.078 & 0.783 & 0.517 & 4 \\
\hline $\begin{array}{l}\text { Easy } \\
\text { administration of } \\
\text { HR functions }\end{array}$ & -0.106 & 0.657 & 0.539 & 2 \\
\hline $\begin{array}{l}\text { Faster HR } \\
\text { transactions }\end{array}$ & -0.224 & 0.706 & 0.455 & 5 \\
\hline $\begin{array}{l}\text { Reliability of } \\
\text { information }\end{array}$ & -0.012 & 0.833 & 0.539 & 2 \\
\hline $\begin{array}{l}\text { Faster } \\
\text { communication }\end{array}$ & 0.475 & 0.777 & 0.83 & 1 \\
\hline
\end{tabular}

The data for the factors in table-1 were used to formulate the MOLP model (1) for the factors with respect to the four mentioned criteria. After solving the equivalent LP models (2) and (3) for the MOLP 
model (1), the benchmark value for the criteria, viz., recruitment, performance appraisal, grievance redressing and retirement and voluntary vacation were found to be $0.174,0.16,0.175$ and 0.165 respectively. Keeping this point as the frame of reference, these criteria were re-standardized in the range $[-1,1]$ as discussed in model (4). The two measures of the effectiveness, viz., the average value $\left(A V^{R}\right)$ and average distance $\left(A D^{R}\right)$ were calculated. The effectiveness value of the factors as per these two measures were assessed based on the model (5) and are presented in the table-2 along with their corresponding ranks. Hence, these values in the range $[0,1]$ represent the degree of closeness of these factors to the benchmark value obtained as a compromise solution of the MOLP model designed from the criteria-alternatives matrix for the HRIS.

\section{Limitations}

This methodology is applicable to problems having fewer number of criteria as well as alternatives as it uses Saaty's (1980) AHP method do determine the weights of the criteria and the alternatives in a pairwise comparison manner. As the number of criteria and alternatives increase, it becomes difficult to get consistent judgement matrices in order to get normalised weights for the criteria and the alternatives. However, in case more number of alternatives with lesser number of criteria, a normalized data matrix may be used for the weights of the alternatives where criteria weights may be generated from Saaty's AHP analysis of pairwise comparison data in the ordinal scale.

\section{Conclusions}

This paper presents a methodology to determine relative effectiveness of alternatives with respect to multiple number of criteria based on the pairwise comparison data obtained from Saaty's scale. Although, the AHP methodology of Saaty provides relative weights of alternatives in a multi-criteria framework, the present paper is an extension of AHP for the determination of effectiveness value of the alternatives in the presence of multiple number of effective criteria. In this approach, the concept of a benchmark point is used having the highest common attainment level as well as the maximum average value of the effectiveness criteria. A multi-objective linear programming model is formulated and solved for an efficient point, which is treated as the benchmark. Keeping this point as the frame of reference, the effectiveness value of the alternatives are found out taking into consideration their relative closeness to the benchmark point. Hence, the effectiveness value becomes a reference based measure obtained from peer comparisons through a multi-criteria decision analysis. This method is easy to use and has a scope for wider applications in various performance measurement.

\section{Key References}

Golany, B. (1988). An Interactive MOLP Procedure for the Extension of DEA to effectiveness analysis, Journal of Operational Research Society, 39(8), 725-734.

Golany, B., \& Tamir, E. (1995). Evaluating efficiency-effectiveness-equality trade-offs: A data envelopment analysis, Management Science, 41(7), 1172-1184.

Marsh, H. W., \& Bailey, M. (1993). Multi-dimensionality of students' evaluation of teaching effectiveness: A profile analysis, Journal of Higher Education, 64(1) 1-18.

Mouzas. S. (2006). Efficiency versus effectiveness in business networks, Journal of Business Research, 59, 1124-1132.

Saaty, T. L. (1980). The analytic hierarchy process. New-York: McGraw Hill. 